\title{
ARTICLE
}

Received 00th January 20xx, Accepted 00th January 20xx

DOI: 10.1039/x0xx00000x

www.rsc.org/

\section{Triazine-based molecular glasses frustrate the crystallization of barbiturates}

\begin{abstract}
Audrey Laventure, ${ }^{a}$ Dominic Lauzon, ${ }^{a}$ Christian Pellerin,,${ }^{*, a}$ and Olivier Lebel ${ }^{*, b}$
Hydrogen bonding is a key element of supramolecular chemistry and is often used in crystal engineering to direct crystal packing. In particular, systems where motifs with multiple hydrogen $(\mathrm{H})$ bonds are present, such as the donor-acceptordonor - acceptor-donor-acceptor (DAD-ADA) synthon, can be used to generate various supramolecular architectures. However, $\mathrm{H}$-bonding can also be used to frustrate crystallization if it impedes an efficient molecular packing, instead resulting in glass formation. Herein, triazine-based molecular glass-formers, which can form multiple hydrogen bonds and show outstanding resistance to crystallization, are strategically used to hinder the crystallization of barbiturates derivatives, even in blends with low molar fractions, depending on the structure of the glass-former. Besides the strong DAD-ADA motifs, the molecules can form several sub-optimal motifs that serve to hinder the crystallization of the barbiturate component during solvent evaporation or cooling. A triazine derivative with a covalently bound barbituric acid moiety was also synthesized, and did also not show any crystallization, showing that the presence of strong and predictable hydrogen bonding motifs does not necessarily contribute to crystallization. Our results highlight molecular design guidelines to hinder the crystallization of a compound, either by covalent functionalization or by blending with a glass-former capable of establishing similar interactions, thus leading to a variety of motifs for glass engineering.
\end{abstract}

\footnotetext{
a. Département de chimie, Université de Montréal, Montréal, QC, H3C 3J7, Canada. E-mail: c.pellerin@umontreal.ca

b. Department of Chemistry and Chemical Engineering, Royal Military College of Canada, Kingston, ON, K7K 7B4, Canada. E-mail: olivier.lebel@rmc.ca

Electronic Supplementary Information (ESI) available: DSC scan of $\mathrm{N}, \mathrm{N}^{\prime}$ dimethylbarbital, additional $\mathrm{T}_{\mathrm{g}}$ data and polarized microcopy images of glassbarbiturate blends, NMR spectra of barbiturate glasses $\mathbf{G B}$ and $\mathbf{G B}_{\mathrm{NMe}}$. See DOI: $10.1039 / \times 0 x x 00000 x$
} 


\section{Journal Name}

\section{ARTICLE}

\section{Introduction}

Hydrogen bonds constitute one of the most iconic types of supramolecular interactions. The implications of hydrogen bonds are widespread in biological systems and include phenomena at the center of life, including water capillarity, molecular recognition, and DNA complementarity. ${ }^{1}$ The impact of hydrogen bonds on the physical properties of materials has led to their strategic use in materials science, both with natural materials such as cellulose or spider silk, and with synthetic materials such as nylons and Kevlar. ${ }^{2}$

Hydrogen bonding is widely used in crystal engineering to attempt to direct crystal packing, and as such is regarded as a directional interaction. ${ }^{3}$ On the other hand, $\mathrm{H}$-bonding only involves a limited number of atoms and does not constrain the molecules in a single specific conformation, and as a consequence, the molecules still retain most degrees of freedom. ${ }^{4}$ Therefore, even though hydrogen bonding is considered a directional interaction, it does not necessarily promote the crystallization process itself. In fact, it has been shown that in compounds with slow crystallization kinetics, hydrogen bonding can contribute to frustrate crystallization even further by providing additional cohesion between molecules, thereby limiting molecular mobility in the amorphous phase, ${ }^{5}$ or by providing multiple sub-optimal association motifs between molecules that favor irregular packing. With strategically designed molecular structures, extremely long-lived glasses can be obtained where hydrogen bonding is present, even in the viscous state, and contributes to maintaining the amorphous state. ${ }^{5,6}$ Mexylaminotriazines (mexyl: 3,5-dimethylphenyl) are one such family of molecular glass-formers, i.e. compounds that can readily form kinetically stable glassy phases even upon extremely slow cooling from the melt state, where hydrogen bonds are involved in the supramolecular packing and have a pronounced impact on the glass-forming properties, glass kinetic stability, and glass transition temperature $\left(T_{g}\right)$ of the compounds. ${ }^{4,6,7}$

While mexylaminotriazines molecular glasses (see Scheme 1) can form pairs of hydrogen bonds between $\mathrm{NH}$ groups and $\mathrm{N}$ triazine atoms with up to two neighboring molecules (Scheme 2 ), this self-assembly pattern is not very strong compared to some other supramolecular synthons involving hydrogen bonds $\left(K_{\mathrm{a}} \approx 1-2 \mathrm{M}^{-1}\right.$ in $\mathrm{CDCl}_{3}, \Delta \mathrm{H}$ of $\mathrm{H}$-bond formation $=-17 \mathrm{~kJ} / \mathrm{mol}$ in the bulk solid state).5,6 Arguably, the weak nature of such patterns can contribute to frustrating crystallization because the molecular assembly is reversible and molecules can adopt different $\mathrm{H}$-bonding motifs in dynamic equilibrium with one another.
Diarylmelamine derivatives possess donor-acceptor-donor (DAD) motifs and are known to self-assemble with barbiturates, which possess complementary acceptor-donor-acceptor (ADA) motifs, through a triple-hydrogen-bonded supramolecular synthon (Scheme 2). ${ }^{8}$ This type of synthon has been used in crystal engineering to obtain crystals containing supramolecular ribbon or rosette motifs, depending on the structures of the substituents, ${ }^{9,10}$ but also in self-assembled monolayers. ${ }^{11,12}$ These interactions $(\mathrm{NH}---\mathrm{O}=\mathrm{C}, \mathrm{N}---\mathrm{NH}$ and $\mathrm{NH}---\mathrm{O}=\mathrm{C}$ ) are much stronger than the $\mathrm{NH}---\mathrm{N}$ hydrogen bond pairs of mexylaminotriazines, and as a result, would provide stronger cohesion to the molecules. While most glass-forming mexylaminotriazine derivatives can adopt at least one conformation with a DAD motif, derivatives with an alkylamino headgroup at the 2-position of the triazine ring (Scheme 1) offer the possibility to form a DAD motif in three different possible orientations, and as a result are promising candidates to form supramolecular complexes with barbiturate derivatives involving DAD-ADA supramolecular synthons. Such blends are of interest for crystal engineering, ${ }^{13,14}$ but also for glass engineering when the blend results in an amorphous solid, which is especially relevant to the pharmaceutical industry where co-amorphous excipients are sought. ${ }^{15-17}$ Such interactions have also been exploited to impede the crystallization of thymine when blended with diaminotriazine. ${ }^{18}$

Scheme 1. Molecular structures of the compounds under study.

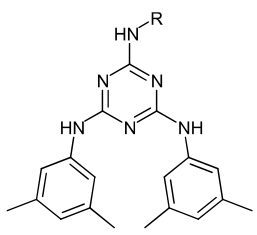

Molecular Glasses

$G_{M e}: R=M e$

$G_{\mathrm{Et}}: R=E \mathrm{t}$

$G_{P r}: R=P r$

$G_{B u}: R=B u$

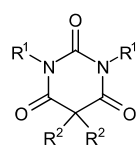

Barbituric Acids

B: $R^{1}=H, R^{2}=E t$

$B_{\mathrm{NMe}}: R^{1}=M e, R^{2}=E$

$B_{B u}: R^{1}=H, R^{2}=B u$

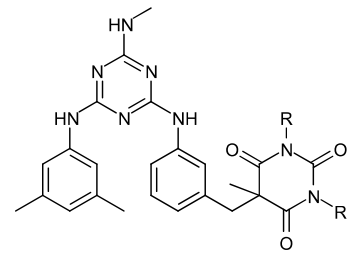

Covalent Derivatives

GB: $\mathrm{R}=\mathrm{H}$

$\mathrm{GB}_{\mathrm{NMe}}: \mathrm{R}=\mathrm{Me}$
In a recent study, we have shown that while they are moderately strong and relatively predictable, hydrogen bonds do not involve a large portion of the molecules' surface and as a result they impose few constraints on the conformation of the molecules or on other intermolecular interactions with neighboring molecules. ${ }^{4}$ However, the impact of stronger multiple hydrogen bonding motifs on the relative propensity of the compounds to either crystallize or form glasses is still unclear. Herein, mixtures of various mexylaminotriazine glass- 
formers with barbiturates, which can establish strong and directional $\mathrm{H}$-bonds, ${ }^{19}$ are prepared and characterized, and mexylaminotriazine glasses incorporating covalently bonded barbiturate groups are synthesized. These model systems reveal the strong effect of glass-formers on the capability of barbiturates to crystallize in spite of the possibility of forming stronger and more directional $\mathrm{H}$-bonding motifs. The barbiturate could stay amorphous even with as little as $20 \mathrm{~mol} \%$ of the molecular glass when short alkyl chains are present on both components (Me for the glass, Et for the barbiturate), whereas longer alkyl chains on either component allowed the barbiturate to partially crystallize out of the blends when their molar fraction is higher than $50 \%$. The $\mathrm{T}_{\mathrm{g}}$ of the blends are also found to correlate with the $T_{\mathrm{g}}$ values of the pure components and not to be raised by the possibility of forming strong directional $\mathrm{H}$-bonds, showing the importance of the availability of multiple sub-optimal interacting motifs on the glass-forming properties.

\section{Results and Discussion}

\section{Synthesis}

Scheme $1^{\ddagger}$ presents the compounds under study. Molecular glasses $\mathbf{G}_{\mathrm{Me}}-\mathbf{G}_{\mathrm{Bu}}$ were synthesized following previously published procedures. ${ }^{20,21}$ Barbiturate-functionalized compounds $\mathbf{G B}$ and $\mathbf{G B}_{\mathrm{NM}}$ were synthesized by the nucleophilic substitution of 5-methylbarbituric acid and 5,N, $\mathrm{N}^{\prime}$ trimethylbarbituric acid on previously published bromomethyl precursor $\mathbf{1}^{22}$ in the presence of $\mathrm{N}, \mathrm{N}$-diisopropylethylamine (DIEA) in DMF/ $\mathrm{H}_{2} \mathrm{O} 3: 1$ or $\mathrm{DMF}$, respectively, affording compounds $\mathbf{G B}$ and $\mathbf{G B}_{\mathrm{NM}}$ in $90 \%$ yield (Scheme 3 ). Both compounds could be conveniently purified by precipitation in $\mathrm{H}_{2} \mathrm{O}$, followed by thorough drying of the products.

Scheme 2. Examples of common hydrogen bonding motifs of aminotriazine and barbiturate derivatives.

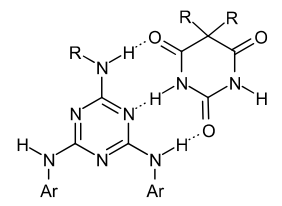

DAD-ADA

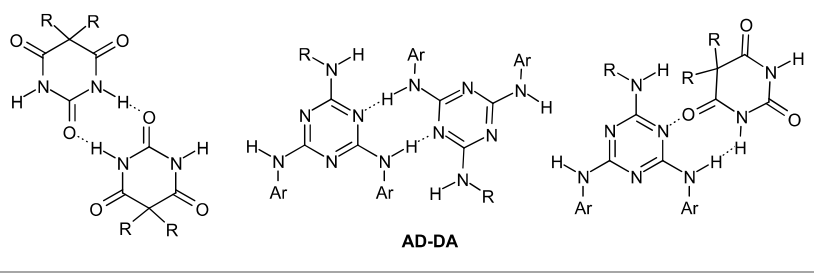

Scheme 3. Synthesis of covalent barbiturate-functionalized molecular glass derivatives $\mathbf{G B}$ and $\mathbf{G B}_{\mathrm{NMe}}$.

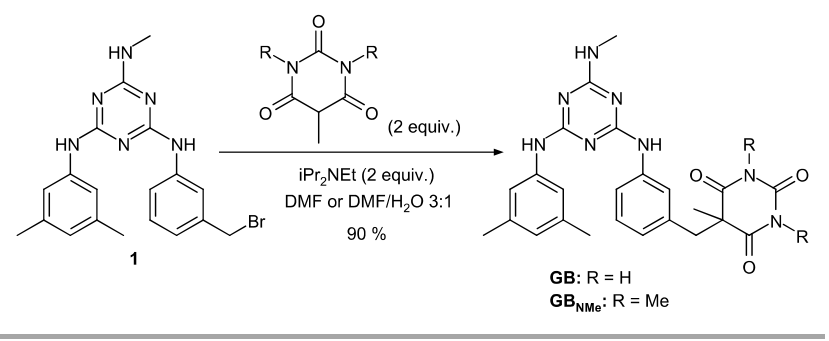

\section{Comparison of the solution and solid-state behaviors}

\section{Association constants}

The presence of DAD-ADA motifs in mexylaminotriazinebarbiturate blends is expected to lead to stronger association than their respective self-association. To confirm that this is indeed the case, the association constants for compounds $\mathbf{G}_{\mathbf{M e}}$ and $\mathbf{G}_{\mathrm{Bu}}$, their blends with barbital (B) and N, $\mathrm{N}^{\prime}$-dimethylbarbital ( $\mathrm{B}_{\mathrm{NMe}}$ ), barbital $\mathrm{B}$ itself, and $\mathrm{N}, \mathrm{N}^{\prime}$-dimethylbarbituratesubstituted compound $\mathbf{G B}_{\mathrm{NMe}}$, were measured by variable concentration ${ }^{1} \mathrm{H}$ NMR spectroscopy in $\mathrm{CDCl}_{3}$. The $K_{\mathrm{a}}$ values for the barbital blends were estimated assuming a 1:1 association. ${ }^{23,24}$ The respective $K_{\mathrm{a}}$ were calculated using the WinEQNMR2 software ${ }^{25}$ and are listed in Table 1 . The $K_{\mathrm{a}}$ values for compound $\mathbf{G}_{\mathrm{Me}}$ are in agreement with previously published values. ${ }^{5}$ For compounds $\mathbf{G}_{\mathbf{M e}}$ and $\mathbf{G}_{\mathrm{Bu}}$, there are two distinct $\mathbf{N H}$ signals for the linker $\mathrm{NH}$ groups and headgroup $\mathrm{NH}$ group, and the $K_{\mathrm{a}}$ values for both could be measured. $K_{\mathrm{a}}$ values are between 1.5 and $3.6 \mathrm{M}^{-1}$ with the linker NH typically associating slightly more strongly than the headgroup $\mathrm{NH}$, probably a consequence of the stronger electron-donating character of the alkyl chain that decreases the $\mathrm{H}$-bond donor capability of the headgroup $\mathrm{NH}$. Barbital B shows a slightly higher $K_{\mathrm{a}}\left(10 \mathrm{M}^{-1}\right)$, as it can also form pairs of hydrogen bonds between molecules and the oxygen atoms are stronger hydrogen bond acceptors than the nitrogen atoms of $\mathbf{G}_{\mathrm{Me}}$ and $\mathbf{G}_{\mathrm{Bu}}$. Strikingly, their respective blends with $\mathbf{B}$ show $K_{\mathrm{a}}$ three orders of magnitude higher (between 2000 and $4000 \mathrm{M}^{-1}$ ), which indicates the formation of stronger supramolecular motifs. ${ }^{26}$ This behavior, i.e. stronger interactions in the blends than for the individual components, has also been observed in blends of barbiturates and citric acids. ${ }^{27}$ In contrast, the blends of $\mathbf{G}_{\mathrm{Me}}$ with $\mathbf{B}_{\mathrm{NMe}}$, and $\mathbf{G B}_{\mathrm{NMe}}$, which incorporates a covalently bonded $N, N^{\prime}$ dimethylbarbiturate group, show weak association $\left(K_{\mathrm{a}}=0.75\right.$ to $1.8 \mathrm{M}^{-1}$ ) comparable to those of pure compounds $\mathbf{G}_{\mathrm{Me}}$ and $\mathbf{G}_{\mathrm{Bu}}$, which is to be expected for these systems in which the DAD-ADA motif is absent. Unfortunately, the association constant could not be measured for barbiturate-functionalized mexylaminotriazine $\mathbf{G B}$, which combines the $\mathbf{G}_{\mathbf{M e}}$ and $\mathbf{B}$ moieties and is therefore a unimolecular analogue of their blend, because of its low solubility in $\mathrm{CDCl}_{3}$. This in itself is an indication of strong intermolecular cohesion likely due to the selfcomplementary DAD and ADA motifs. 
Table 1. Association constants $\left(K_{\mathrm{a}}\right)$ for glass-formers $\mathbf{G}_{\mathrm{Me}}, \mathbf{G}_{\mathrm{Bu}}$ and $\mathbf{G B}_{\mathrm{NMe}}$, barbital $\mathbf{B}$, and blends of $\mathbf{G}_{\mathrm{Me}}$ and $\mathbf{G}_{\mathrm{Bu}}$ with $\mathbf{B}$.
Compound

$\mathbf{G}_{\mathrm{Me}}$
$\mathbf{G}_{\mathrm{Bu}}$
$\mathbf{G}_{\mathrm{Me}}-\mathbf{B}$
$\mathbf{G}_{\mathrm{Bu}}-\mathbf{B}$
$\mathbf{G}_{\mathrm{Me}}-\mathbf{B}_{\mathrm{NMe}}$
$\mathbf{G B}_{\mathrm{NMe}}$

$K_{\mathrm{a}}\left(\mathrm{M}^{-1}\right)$

Headgroup NH

Linker NH

3000

1.8
0.75

B

2.4
3.6
2000
3800

1.8

1.6

10

1.5
1.5
4000
3000

\section{Thermal properties of molecular glass-barbital blends}

Blends of barbital B or N,N'-dimethylbarbital $\mathbf{B}_{\mathrm{NM}}$ with molecular glass $\mathbf{G}_{\mathrm{Me}}$ in molar fractions ranging from $10 \%$ to $90 \%$ were prepared by evaporation from THF solution. The heating thermograms measured by differential scanning calorimetry (DSC) are shown in Figure 1, and show the presence of a glass transition event at decreasing temperature with decreasing molar fraction of glass $\mathbf{G}_{\mathbf{M e}}$, with no undesirable crystallization upon heating. Unfortunately, the temperature could not be increased past $80^{\circ} \mathrm{C}$ for the barbiturate-containing blends to avoid thermal decomposition or sublimation of the barbiturate.
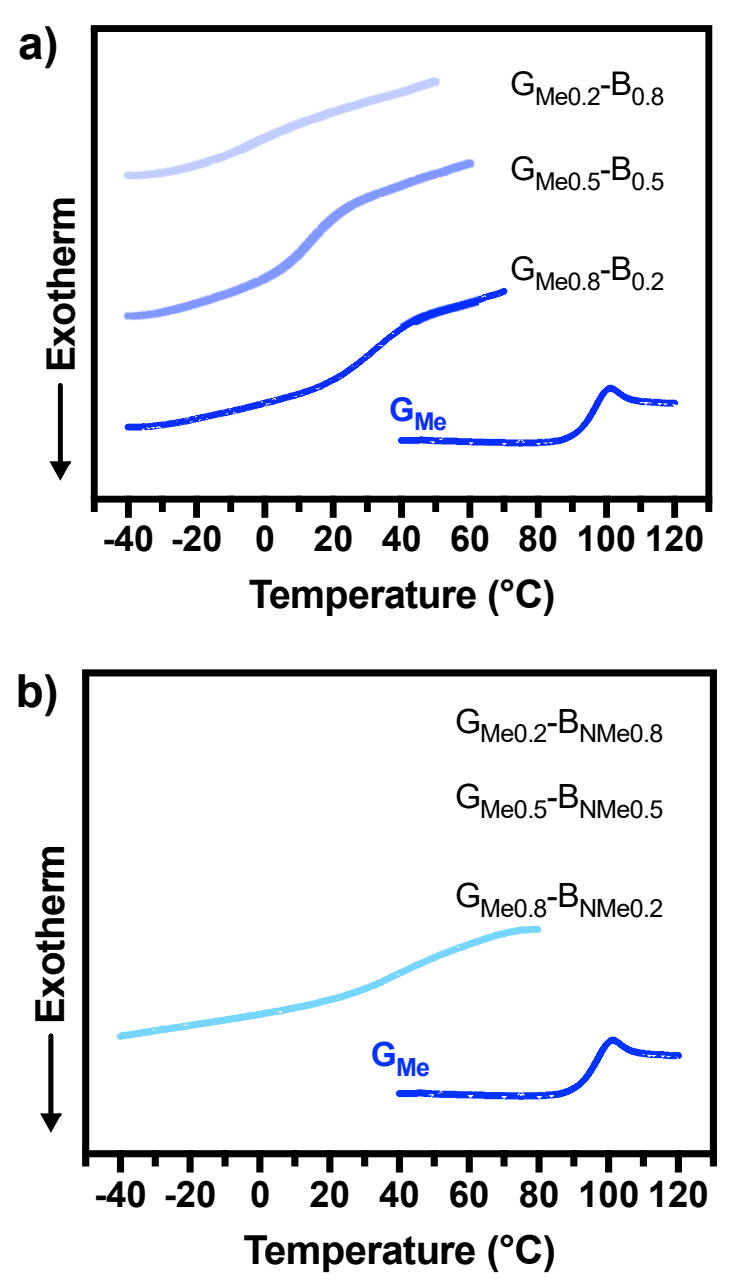

Figure 1. DSC heating traces for A) $\mathbf{G}_{\mathrm{Me}^{-}}-\mathbf{B}$, and B) $\mathbf{G}_{\mathrm{Me}^{-}}-\mathbf{B}_{\mathrm{NMe}}$ blends at the molar fractions indicated, and for pure GMe molecular glass.

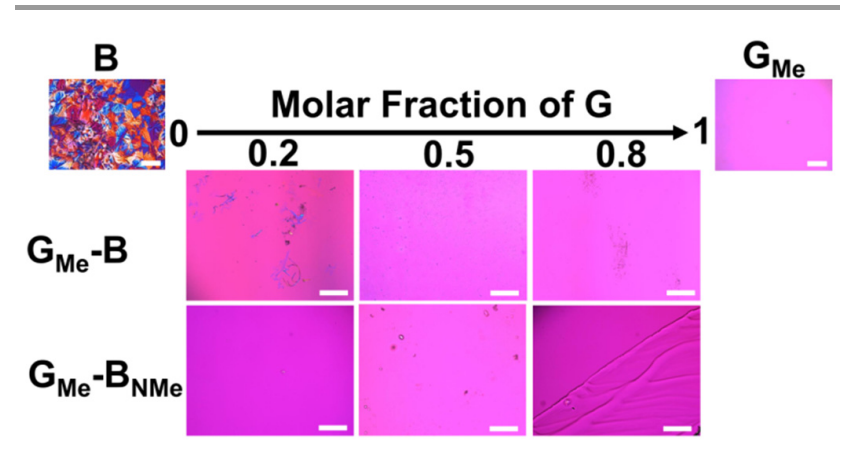

Figure 2. Polarized optical microscopy images of blends of $\mathbf{G}_{\mathrm{Me}}: \mathbf{B}$ and $\mathbf{G}_{\mathrm{Me}}: \mathbf{B}_{\mathrm{NMe}}$. Scale bars correspond to $100 \mu \mathrm{m}$.

Thin films of the blends were also deposited by drop-casting from THF solution and observed by polarized optical microscopy (Figure 2). While barbital B itself yields a polycrystalline film and molecular glass $\mathbf{G M}_{\mathbf{e}}$ forms a completely amorphous film, as 
expected, the blends were all found to be essentially amorphous for molar fractions of glass $\mathbf{G}_{\mathrm{Me}}$ as low as 0.2 . This suggests that $\mathbf{G}_{\mathrm{Me}}$ not only shows outstanding resistance to crystallization by itself, but also can prevent other compounds from crystallizing, even as a minor component ( $20 \mathrm{~mol} \%$ ) in a mixture. Additionally, this is not necessarily due to the formation of hydrogen bonded assemblies between $\mathbf{B}$ and glass $\mathbf{G}_{\mathrm{Me}}$, as each barbital molecule can only form hydrogen bonds with two molecules of compound $\mathbf{G}_{\mathbf{M e}}$, assuming that a minimum of two hydrogen bonds are formed between molecules.

In glass-barbital blends, hydrogen bonds can form along several different patterns, including the optimal DAD-ADA motif, but also several $A D-D A$ and $A-D$ motifs; $H$-bonding can also occur between different partners (G-G, G-B, B-B). The presence of these competing interactions can increase the viscosity of the system, ${ }^{28}$ thereby hindering the segregation and crystallization of $\mathbf{B}$ from the blend, even in the presence of a limited amount of molecular glass. In addition, since the $T_{g}$ of the molecular glass is significantly higher than that of barbital (see below), the blends containing at least $70 \%$ glass-former show $T_{\mathrm{g}}$ values above ambient temperature, which limits the reorganization of the barbital molecules and improves the kinetic stability of the blend in the glassy state. ${ }^{29}$

It must nonetheless be noted that when the solvent evaporation rate is slow, for example during evaporation with a rotary evaporator leading to thick sample layers, a fraction of the barbital crystallizes before the evaporation is complete, thereby altering the $T_{g}$ of the blends. Indeed, the sub-optimal AD-DA and A-D hydrogen bonding motifs mentioned above are more likely to be disrupted than the ideal ADA-DAD motifs in the presence of sufficient solvent to plasticize the system (such that its effective $T_{g}$ is below ambient), enabling $\mathbf{B}$ molecules to reorganize to optimize their intermolecular interactions. The nucleation of barbital crystals and phase segregation from the glass mixture then becomes a competing process to the formation of completely amorphous blends, leading to a small fraction of $\mathbf{B}$ crystals embedded in the glassy mixture matrix. It is thus likely that barbital crystallization can be mitigated by modifying the parameters of the evaporation to increase its speed and to decrease layer thickness (container size, pressure, temperature, etc.). For this reason, all the blend samples reported herein were prepared by drop-casting thin films. Sample preparation processes involving a faster solvent evaporation, such as spin-coating, are also expected to produce amorphous mixtures.

As $\mathbf{G}_{\mathbf{M e}}$ can adopt a single DAD motif when in the proper conformation, a 2:1 glass:barbiturate molar ratio mixture, in which the molecules would form trimolecular complexes with two DAD-ADA motifs, is expected to yield optimal hydrogen bonding, and presumably higher $\mathrm{T}_{\mathrm{g}}$ values. Despite the presence of stronger hydrogen bonding interactions, Figure 3 shows that the $T_{g}$ values of the blends rather decrease when increasing the molar fraction of $\mathbf{B}$ from $94{ }^{\circ} \mathrm{C}$ for the pure $\mathbf{G}_{\mathbf{M e}}$ to a minimal $\mathrm{T}_{\mathrm{g}}$ of $-20{ }^{\circ} \mathrm{C}$ at $20 \mathrm{~mol} \%$ of glass (no $\mathrm{T}_{\mathrm{g}}$ was detectable on the DSC trace of the 10 mol\% blend). The $\mathrm{T}_{\mathrm{g}}$ of a mixture of two glassforming components normally follows a weighted average of the $T_{\mathrm{g}}$ values of each individual component. ${ }^{30.31}$ Some cases have been reported where there is a positive $T_{g}$ deviation to this weighted average in binary blends due to strong interactions between both components. ${ }^{32-34}$ In the current case, however, both components can already interact with themselves through weaker motifs, thereby likely mitigating the effect of the presence of DAD-ADA motifs on the $T_{g}$ of the blends. Though $B$ readily crystallizes, it would in principle be possible to obtain a glassy sample through rapid quenching. Unfortunately, barbital starts to sublime before melting, therefore it was not possible to measure its $T_{g}$ directly. Nevertheless, the $T_{g}$ of $\mathbf{B}$ could be extrapolated from Figure 3 to be between -30 and $-20^{\circ} \mathrm{C}$. While this value may seem low for a compound capable of forming hydrogen bonds, it must be remembered that $\mathbf{B}$ can $\mathrm{H}$-bond along numerous motifs, several of which are sub-optimal, and that its two ethyl chains can adopt multiple conformations that prevent efficient packing in the glassy state. Coupled with the fact that $T_{\mathrm{g}}$ tends to increase with molecular mass, ${ }^{35}$ it is reasonable for barbital to undergo glass transition at such a low temperature. For example, higher molecular weight analogues pentobarbital and hexobarbital undergo glass transition at 6 and $13{ }^{\circ} \mathrm{C}$, respectively, ${ }^{36}$ while citric acid, a relatively small tricarboxylic acid, shows a $\mathrm{T}_{\mathrm{g}}$ of $10{ }^{\circ} \mathrm{C}$ even if it can form extensive hydrogen bonding. ${ }^{36}$

In order to decouple the impact of stronger hydrogen bonding motifs from the impact of the introduction of a second component, blends of molecular glass $\mathbf{G}_{\mathbf{M e}}$ with $\mathbf{B}_{\mathrm{NMe}}$, which cannot participate in multiple hydrogen bonding motifs, were prepared and their glass-forming behavior was studied by DSC (Figures $1 \mathrm{~B}$ and 3 ) and polarized optical microscopy (Figure 2). The blends of $\mathbf{G}_{\mathrm{Me}}$ with $\mathbf{B}_{\mathrm{NM}}$ showed a similar behavior as those with barbital $\mathbf{B}$, including the formation of completely amorphous films and a decreasing $T_{\mathrm{g}}$ profile reaching a $\mathrm{T}_{\mathrm{g}}$ close to $-20{ }^{\circ} \mathrm{C}$ at $10 \mathrm{~mol} \%$ of $\mathbf{G}_{\mathrm{Me}}$. In this case, it was possible to generate a partially glassy sample of pure $\mathbf{B}_{\mathrm{NM}}$ by fast cooling with liquid nitrogen, which showed a $\mathrm{T}_{\mathrm{g}}$ of $-42^{\circ} \mathrm{C}$ (see Figure S1 in Electronic Supplementary Information, ESI), a value consistent with the $T_{\mathrm{g}}$ that can be extrapolated in Figure 3 . The presence or absence of strong DAD-ADA motifs thus has seemingly little impact on the $T_{g}$ values of the blends, the added disorder generated by the presence of two components and the intrinsically low and similar $\mathrm{T}_{\mathrm{g}}$ of both pure barbital derivatives being the predominant factor. This result highlights that, at least in this case, the association constants calculated in solution are not an efficient predictor of the behavior of the same blend in the solid state, compared to using the Flory-Huggins interaction parameter. ${ }^{37}$ Indeed, the association constant of the $\mathbf{G}_{\mathbf{M e}}-\mathbf{B}_{\mathrm{NMe}}$ blend was three orders of magnitude less than for the $\mathbf{G}_{\mathrm{Me}}-\mathbf{B}$ blend yet they behave very similarly in the bulk. The interplay between the steric interactions and the pre-organization in solution, ${ }^{36}$ (which may be more predictable when interactions between the components of the blend are directional) ${ }^{38}$ are also important to consider when predicting the solid-state behavior, probably more than the association constant in solution. 


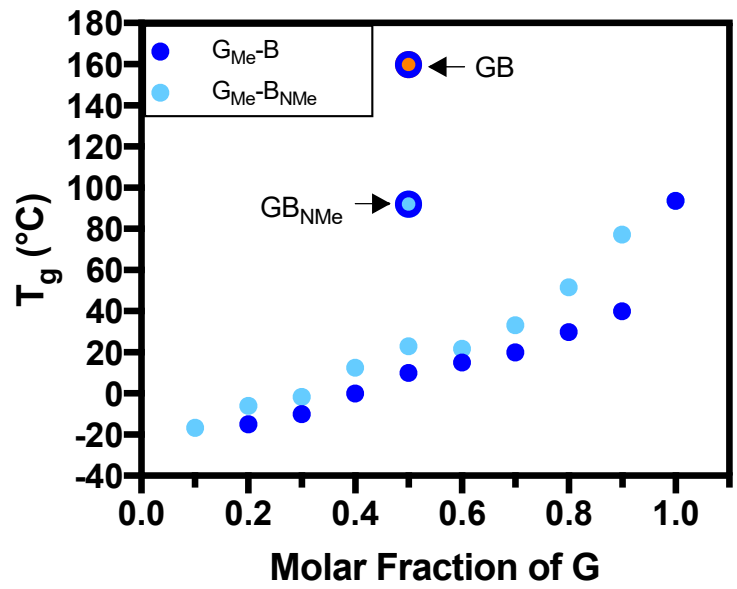

Figure 3. $T_{\mathrm{g}}$ of the $\mathbf{G}_{\mathrm{Me}^{-}}-\mathbf{B}$ or $\mathbf{G}_{\mathrm{Me}}-\mathbf{B}_{\mathrm{NM}}$ blends as a function of their molecular glass composition.

Influence of alkyl chain length on glass-forming properties

To validate the importance of suboptimal hydrogen bonding motifs on the capability of glass-former $\mathbf{G}_{\mathrm{Me}}$ to prevent the crystallization of barbitals $\mathbf{B}$ and $\mathbf{B}_{\mathrm{NM}}$, blends of $\mathbf{B}$ were also prepared with glasses $\mathbf{G}_{\mathrm{Et}}-\mathbf{G}_{\mathrm{Bu}}$, in which the headgroup amine is substituted with an ethyl, propyl and butyl chain, respectively. While the drop-cast blends did not show any signs of crystallization with molar fractions of $\mathbf{G}_{\mathbf{M e}}$ as low as $20 \%$, polarized optical microscopy reveals the presence of crystals in films of the blends of $\mathbf{B}$ with all three compounds $\mathbf{G}_{\mathrm{Et}}-\mathbf{G}_{\mathrm{Bu}}$ (Figure 4). Extensive crystallization occurs when the $\mathbf{G}$ molar fraction is below equimolar.

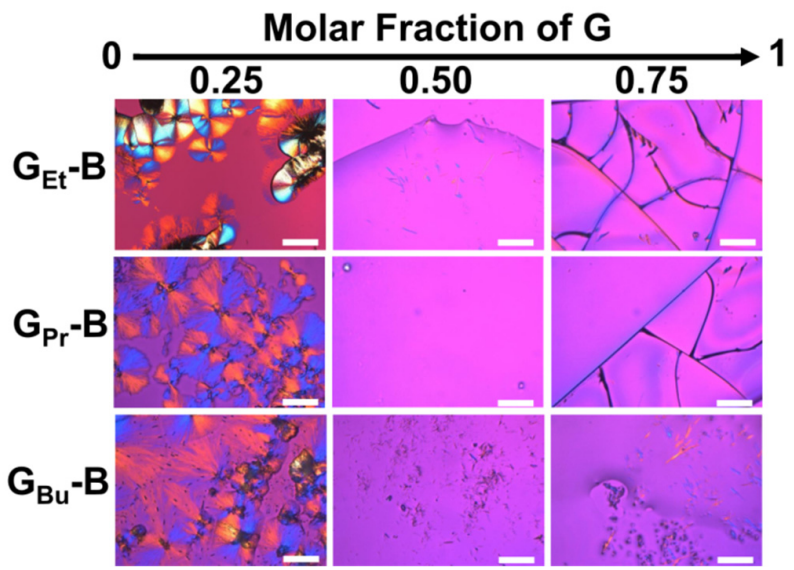

Figure 4. Polarized optical microscopy images for $\mathbf{G}_{\mathrm{Et}}-\mathbf{B}, \mathbf{G}_{\mathrm{pr}}-\mathbf{B}$ and $\mathbf{G}_{\mathrm{Bu}}-\mathbf{B}$ blends. For $\mathbf{G}_{\mathrm{Bu}}$ B blends, the left image corresponds to a 0.2 molar fraction of molecular glass and the right image, to a 0.8 molar fraction of molecular glass. Scale bars correspond to $100 \mu \mathrm{m}$.

While the $T_{\mathrm{g}}$ of pure glasses $\mathbf{G}_{\mathrm{Me}}-\mathbf{G}_{\mathrm{Bu}}$ ranges from 94 to $65{ }^{\circ} \mathrm{C}$, respectively, the $\mathrm{T}_{\mathrm{g}}$ values of the blends with glass molar fractions higher than $50 \%$ are closely similar (Figure 5 ). The size of the alkyl group thus does not seem to impact the $T_{g}$ of the blends. However, a gradual increase in $\mathrm{T}_{\mathrm{g}}$ can be observed as the glass molar fraction decreases below 50 mol\%, in sharp contrast to the continuously decreasing trend observed for the blends of $\mathbf{B}$ with glass $\mathbf{G}_{\mathbf{M e}}$. While these observations seem surprising, they can be rationalized by the fact that the barbital undergoes partial crystallization in these blends when the glassformer fraction is low. This means that the molar fraction of glass-former in the amorphous phase actually increases when barbital crystallizes out of the blend, and that the $T_{g}$ values measured are a reflection of the effective composition in the amorphous phase as opposed to the nominal composition.

This behavior, which contrasts with that observed with glassformer $\mathbf{G}_{\mathbf{M e}}$, is likely due to two factors. Firstly, the lower $T_{\mathrm{g}}$ values of $\mathbf{G}_{\mathrm{Et}}-\mathbf{G}_{\mathrm{Bu}}$ lead to blends in which viscosity is lower and where the barbital molecules can more freely reorganize. Additionally, the higher steric hindrance caused by the primary alkyl chains of glasses $\mathbf{G}_{\mathrm{Et}}-\mathbf{G}_{\mathrm{Bu}}$ which are slightly more hindered than the methyl group of glass $\mathbf{G}_{\mathbf{M}}$, hinders the formation of hydrogen-bonded assemblies between barbital and glassforming molecules. This is evidenced by the association constant $\left(K_{\mathrm{a}}\right)$ of the linker $\mathrm{NH}$ group of butylamino glass $\mathbf{G}_{\mathrm{Bu}}$ being higher than that of its alkyl $\mathrm{NH}$ headgroup in the mixtures with B, while the opposite is found for mixture of B with methylamino glass $\mathbf{G}_{\mathrm{Me}}$. Unfortunately, it was not possible to further confirm this hypothesis using infrared spectroscopy because of strong overlap between the various $\mathrm{NH}$ stretching bands and the probable presence of different crystal forms since barbital is known to be a polymorphic system, highlighted, among others, by the different shape of crystals observed in the microscopy images. ${ }^{39,40}$

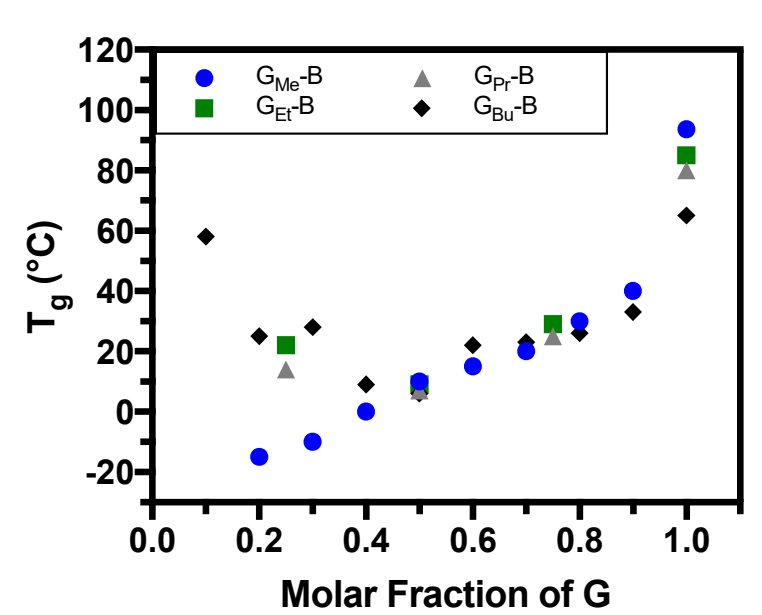

Figure 5. $\mathrm{T}_{\mathrm{g}}$ of the blends of $\mathbf{B}$ with $\mathrm{G}_{\mathrm{Me}}-\mathrm{G}_{\mathrm{Bu}}$ as a function of their molecular glass composition.

The impact of the alkyl chains of the barbital derivative on the glass-forming properties of the blends, including $\mathrm{T}_{\mathrm{g}}$ and crystallization, was also studied. Blends of compound $\mathbf{G}_{\mathbf{M e}}$ with 5,5-dibutylbarbituric acid $\left(\mathbf{B}_{\mathrm{Bu}}\right)$ in various molar fractions were prepared (Figure S2 in ESI). The observed trend mirrors that observed with barbital, with $\mathrm{T}_{\mathrm{g}}$ decreasing with an increasing 
$\mathrm{BBu}$ fraction. The $\mathrm{T}_{\mathrm{g}}$ values are slightly higher than those observed with barbital, which is likely due to $\mathbf{B}_{\mathrm{Bu}}$ possessing a higher $T_{g}$ than $B$ because of its higher molar mass, similarly to analogous pentobarbital and hexobarbital. It should also be noted that in contrast with barbital, $\mathbf{B}_{\mathrm{Bu}}$ crystallized in blends with glass $\mathbf{G}_{\mathbf{M e}}$, small $\mathbf{B}_{\mathrm{Bu}}$ crystals being visible by polarized optical microscopy even with molar fractions as low as $25 \%$ (Figure S3 in ESI). It is not fully clear why glass $\mathbf{G}_{\mathrm{Me}}$ could not prevent the crystallization of $\mathbf{B}_{\mathbf{B u}}$ as efficiently as it did for $\mathbf{B}$ and

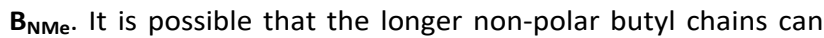
seek to optimize van der Waals interactions between each other, leading to more segregation from the glass-forming $\mathbf{G}_{\mathrm{Me}}$ molecules, thereby favoring crystallization.

\section{Covalent Derivatives}

Compounds $\mathbf{G B}$ and $\mathbf{G B}_{\mathrm{NM}}$ with the barbiturate unit covalently bonded to the glass-forming core of compound $\mathbf{G}_{\mathbf{M e}}$ were synthesized. Both showed good glass-forming ability, with no sign of crystallinity even when a cooling rate of $1{ }^{\circ} \mathrm{C} / \mathrm{min}$ was used. Though the incorporation of the $\mathrm{N}, \mathrm{N}^{\prime}$ dimethylbarbiturate unit in $\mathbf{G B}_{\mathrm{NM}}$ introduces additional hydrogen bond acceptors, it does not impact substantially the association constants for both types of $\mathrm{NH}$ groups in solution, as shown in Table 1, probably because $\mathbf{G B}_{\mathrm{NMe}}$ is incapable of forming DAD-ADA hydrogen bond motifs. Consistently, this compound showed a $\mathrm{T}_{\mathrm{g}}$ value of $92{ }^{\circ} \mathrm{C}$, which is very close to the $\mathrm{T}_{\mathrm{g}}$ of the parent dimexyl analogue $\mathbf{G}_{\mathrm{Me}}$. Compound $\mathbf{G B}$, on the other hand, showed a much higher $\mathrm{T}_{\mathrm{g}}$ value of $160{ }^{\circ} \mathrm{C}$, highlighting the influence of stronger and more extensive hydrogen bonding in the material. Even though the association constant for compound GB could not be measured because of its low solubility in $\mathrm{CDCl}_{3}$, this significantly higher $\mathrm{T}_{\mathrm{g}}$ value suggests that its association constant is likely in the same range or even higher than that of the glass-barbital blend. Interestingly, compound $\mathrm{GB}$ did not show any sign of crystallization upon heating (nor compound $\mathbf{G B}_{\mathrm{NMe}}$ ), hinting that stronger hydrogen bonding patterns still do not necessarily promote crystallization because of their higher directionality when present in systems where crystallization is already frustrated by other structural features.

\section{Conclusions}

In this study, blends of mexylaminotriazine glasses were prepared with various barbituric acids where the molecules can form complementary DAD-ADA hydrogen bonding motifs that are significantly stronger than the hydrogen bonds formed by each individual component. Though the barbituric acids used tend to readily crystallize, the addition of a molecular glassformer capable of establishing $\mathrm{H}$-bonds can lead to a wide range of less optimal hydrogen bonding motifs, thereby slowing crystallization kinetics. As a result, the blends were predominantly amorphous up to molar fractions of barbiturate as high as $70 \%$ (while the glass fraction remained amorphous as expected when partial crystallization occurred). However, subtle structural elements were found to alter this balance between crystallization and glass formation. For example, longer alkyl chains on either the glass-former or the barbituric acid were shown to be less efficient at hindering crystallization. Slower evaporation resulted in a higher fraction of barbiturate crystals, which is to be expected as crystal nucleation and hydrogen-bonded assembly with glass-forming molecules are two competing processes in solution. Derivatives with barbiturate groups covalently bonded to the glass-forming core were synthesized and were shown to remain amorphous in the solid state, indicating that stronger and more directional hydrogen bonding motifs do not necessarily promote crystallization in the solid state when other structural elements frustrate the crystallization process.

Furthermore, this study has shown that it is possible to hinder crystallization by design, not only through covalent bonding with a moiety that promotes glass formation, but also by introducing a glass-forming compound in a blend that is strategically selected to exploit and weaken the structural elements of the target compounds that are the most likely to drive their crystallization. In the current case, the introduction of a second component that is capable of forming multiple redundant hydrogen-bonded motifs (several of which suboptimal) has successfully been used to suppress the crystallization of barbital, even with low molar fractions of glass, but the results can be further generalized with other type of interactions, such as halogen bonding and $\pi$-stacking.

\section{Experimental Section}

\section{General}

2-Methylamino-4-mexylamino-6-(3-

bromomethylphenyl)amino-1,3,5-triazine (1), ${ }^{22}$ methylbarbituric acid, ${ }^{41} 5, \mathrm{~N}, \mathrm{~N}^{\prime}$-trimethylbarbituric acid, ${ }^{42} 5,5$ dibutylbarbituric acid $(\mathrm{BBu}),{ }^{43}$ 2-methylamino-4,6dimexylamino-1,3,5-triazine $\quad\left(\mathbf{G}_{\mathrm{Me}}\right){ }^{21} \quad$ 2-ethylamino-4,6dimexylamino-1,3,5-triazine $\quad\left(\mathrm{G}_{\mathrm{Et}}\right){ }^{21} \quad$ 2-propyl-4,6dimexylamino-1,3,5-triazine $\left(\mathbf{G}_{\mathrm{Pr}}\right)^{21}$ and 2-butylamino-4,6dimexylamino-1,3,5-triazine $\left(\mathbf{G}_{\mathrm{Bu}}\right)^{21}$ were synthesized according to literature procedures. All other reagents and solvents were purchased from commercial sources and used without further purification. FT-IR spectra were recorded on a Tensor 27 FT-IR spectrometer (Bruker Optics) equipped with a liquid nitrogencooled HgCdTe detector and a MIRacle (Pike Technologies) silicon attenuated total reflection (ATR) accessory as films directly cast on the ATR crystal from $\mathrm{CH}_{2} \mathrm{Cl}_{2}$ solution. ${ }^{1} \mathrm{H}$ NMR spectra were recorded on a $400 \mathrm{MHz}$ Bruker AV400 spectrometer at $363 \mathrm{~K}$, and ${ }^{13} \mathrm{C}$ NMR spectra were recorded on a $300 \mathrm{MHz}$ Varian Oxford spectrometer. Decomposition analyses of molecular glasses were obtained using a TGA 2950 thermogravimetric analyzer (TA Instruments) at a heating rate of $50{ }^{\circ} \mathrm{C} / \mathrm{min}$ under a nitrogen atmosphere. $\mathrm{T}_{\mathrm{g}}, \mathrm{T}_{\mathrm{c}}$ and $\mathrm{T}_{\mathrm{m}}$ were recorded by DSC with a PerkinElmer DSC 8500 calorimeter calibrated with indium using a heating rate of $10{ }^{\circ} \mathrm{C} / \mathrm{min}$. Transition temperatures were reported after an initial cycle of heating and cooling. 


\section{Synthesis of barbiturate glass GB}

5-Methylbarbituric acid $(0.284 \mathrm{~g}, 2.00 \mathrm{mmol})$ was suspended in $\mathrm{DMF} / \mathrm{H}_{2} \mathrm{O}(3: 1,4 \mathrm{~mL})$ in a round-bottomed flask equipped with a magnetic stirrer. $\mathrm{IPr}_{2} \mathrm{NEt}(0.348 \mathrm{~mL}, 0.259 \mathrm{~g}, 2.00 \mathrm{mmol}$ ) was added, then the mixture was gently heated until all the components had dissolved. 2-Methylamino-4-mexylamino-6(3-bromomethylphenyl)amino-1,3,5-triazine (1) (0.413 g, 1.00 $\mathrm{mmol}$ ) was then added, and the mixture was heated to $60^{\circ} \mathrm{C}$ for $18 \mathrm{~h}$. The mixture was then poured into $\mathrm{H}_{2} \mathrm{O}$, and the resulting precipitate was collected by filtration and abundantly washed with hot $\mathrm{H}_{2} \mathrm{O}$ to afford, after drying, $0.428 \mathrm{~g}$ pure compound $\mathrm{GB}$ (0.902 mmol, 90\%). $\mathrm{T}_{\mathrm{g}} 160{ }^{\circ} \mathrm{C}$; FT-IR (ATR/ $\mathrm{CH}_{2} \mathrm{Cl}_{2}$ ) 3326, 3235, 3017, 2944, 2919, 2853, 2787, 1721, 1697, 1581, 1560, 1513, $1486,1420,1392,1348,1324,1298,1282,1244,1187,1084$, $1037,998,980,886,839,803,765,738,696,686,641 \mathrm{~cm}^{-1} ;{ }^{1} \mathrm{H}$ NMR (400 MHz, DMSO-d $d_{6}, 363$ K) $\delta 10.90$ (br s, 2H), 8.61 (br s, $1 \mathrm{H}), 8.42(\mathrm{br} \mathrm{s}, 1 \mathrm{H}), 7.70(\mathrm{~d}, J=8.3 \mathrm{~Hz} \mathrm{~Hz}, 1 \mathrm{H}), 7.48(\mathrm{~s}, 1 \mathrm{H}), 7.40$ $(\mathrm{s}, 2 \mathrm{H}), 7.14(\mathrm{t}, J=7.8 \mathrm{~Hz}, 1 \mathrm{H}), 6.67(\mathrm{~d}, J=7.6 \mathrm{~Hz}, 1 \mathrm{H}), 6.62(\mathrm{~s}$, $1 \mathrm{H}), 6.56(\mathrm{br} \mathrm{s}, 1 \mathrm{H}), 3.11(\mathrm{~s}, 2 \mathrm{H}), 2.91(\mathrm{~d}, J=4.5 \mathrm{~Hz}, 3 \mathrm{H}), 2.26(\mathrm{~s}$, $6 \mathrm{H}), 1.53(\mathrm{~s}, 3 \mathrm{H}) \mathrm{ppm} ;{ }^{13} \mathrm{C}$ NMR $\left(75 \mathrm{MHz}, \mathrm{DMSO}-d_{6}\right) \delta 173.5$, $166.5,164.5,164.3,150.1,140.6,137.6,135.9,128.6,123.6$, 122.5, 121.8, 121.5, 119.4, 119.0, 118.0, 52.2, 45.5, 27.7, 23.5, 21.7 ppm; HRMS (ESI, $\mathrm{MNa}^{+}$) calcd. for $\mathrm{C}_{24} \mathrm{H}_{26} \mathrm{NaN}_{8} \mathrm{O}_{3} \mathrm{~m} / \mathrm{z}$ : 497.2020, found: 497.2016 .

\section{Synthesis of barbiturate glass $\mathrm{GB}_{\mathrm{NM}}$}

Compound $\mathbf{G B}_{\mathrm{NMe}}$ was prepared from 2-methylamino-4mexylamino-6-(3-bromomethylphenyl)amino-1,3,5-triazine (1) and 5,N, $\mathrm{N}^{\prime}$-trimethylbarbituric acid following a procedure similar to the one used for compound $\mathbf{G B}$ but with DMF as solvent. Yield: $90 \%$; $\mathrm{T}_{\mathrm{g}} 92{ }^{\circ} \mathrm{C}$; FT-IR $\left(\mathrm{ATR} / \mathrm{CH}_{2} \mathrm{Cl}_{2}\right)$ 3366, 3280, 3221, 3132, 3009, 2942, 2919, 2867, 1747, 1677, 1577, 1554, $1509,1487,1421,1381,1360,1321,1298,1288,1258,1241$, 1181, 1135, 1071, 1051, 998, 975, 956, 930, 891, 867, 840, 808, $773,753,699 \mathrm{~cm}^{-1} ;{ }^{1} \mathrm{H}$ NMR (400 MHz, DMSO- $\left.d_{6}, 363 \mathrm{~K}\right) \delta 8.71$ (br s, 1H), 8.39 (br s, 1H), $7.72(\mathrm{~d}, J=8.3 \mathrm{~Hz}, 1 \mathrm{H}), 7.43(\mathrm{~s}, 1 \mathrm{H})$, $7.39(\mathrm{~s}, 2 \mathrm{H}), 7.12(\mathrm{t}, J=7.8 \mathrm{~Hz}, 1 \mathrm{H}), 6.63(\mathrm{~s}, 1 \mathrm{H}), 6.55(\mathrm{br} \mathrm{s}, 1 \mathrm{H})$, $6.51(\mathrm{~d}, J=7.6 \mathrm{~Hz}, 1 \mathrm{H}), 3.08(\mathrm{~s}, 2 \mathrm{H}), 3.02(\mathrm{~s}, 6 \mathrm{H}), 2.91(\mathrm{~d}, J=4.5$ $\mathrm{Hz}, 3 \mathrm{H}), 2.26(\mathrm{~s}, 6 \mathrm{H}), 1.58(\mathrm{~s}, 3 \mathrm{H}) \mathrm{ppm} ;{ }^{13} \mathrm{C} \mathrm{NMR}$ (75 MHz, DMSO$\left.d_{6}\right) \delta 171.8,166.5,164.5,164.2,150.8,140.9,140.5,137.6$, $135.3,128.5,123.7,122.0,120.5,120.2$, 119.2, 119.0, 118.0, 53.1, 48.6, 48.3, 28.4, 27.8, 22.2, 21.7 ppm; HRMS (ESI, $\mathrm{MNa}^{+}$) calcd. for $\mathrm{C}_{26} \mathrm{H}_{30} \mathrm{NaN}_{8} \mathrm{O}_{3} \mathrm{~m} / z$ : 525.2333, found: 525.2339.

\section{Glass-barbiturate blend preparation and characterization}

Solutions of molecular glasses and barbiturates blends were prepared in THF. For DSC measurements, solutions were dropcast directly in the DSC pan to generate approx. $2.5 \mathrm{mg}$ samples and left to dry overnight in a fumehood before being put under vacuum in a dessicator for a few hours and closing them. DSC measurements were conducted with a PerkinElmer DSC 8500 calorimeter, calibrated with indium, using a heating rate of 50 ${ }^{\circ} \mathrm{C} / \mathrm{min}$. The $\mathrm{T}_{\mathrm{g}}$ 's were determined, after an initial cycle of heating and a ballistic cooling, as the average half-height of the heat capacity jump in the second and third heating scans. For polarized optical microscopy studies, the THF solution was directly drop-cast on a microscope glass slide and images were recorded using a Axioscope 2 microscope from Carl Zeiss Microscopy using a wavelength plate. The ${ }^{1} \mathrm{H}$ NMR spectra used to calculate association constants were recorded at room temperature on a Bruker Avance $400 \mathrm{MHz}$ spectrometer.

\section{Conflicts of Interest}

The authors declare no conflicts of interest for the work presented herein.

\section{Acknowledgements}

The authors thank the Natural Sciences and Engineering Research Council (NSERC \#312493), the Fonds de Recherche du Québec - Nature et Technologies (FRQNT \# 2012-PR-147034) and the Canadian Defence Academy Research Programme (CDARP) from RMC for funding. A.L. thanks NSERC for a Vanier graduate scholarship. D.L. thanks NSERC for an undergraduate student research award. The authors are also grateful to Dr. René Gagnon (Université de Sherbrooke) for mass spectrometry analysis.

\section{Notes and references}

¥ Marvin was used for drawing, displaying and characterizing chemical structures, substructures and reactions, Marvin 17.26, 2017, ChemAxon (www.chemaxon.com).

1 T. Steiner, Angew. Chem. Int. Ed., 2002, 41, 48-76.

2 G. A. Jeffrey and W. Saenger, Hydrogen Bonding in Biological Structures, Springer, Berlin, 1991.

3 G. R. Desiraju, Acc. Chem. Res., 2002, 35, 565-573.

4 A. Laventure, T. Maris, C. Pellerin and O. Lebel, Cryst. Growth Des., 2017, 17, 2365-2373.

5 A. Plante, D. Mauran, S. P. Carvalho, J. Y. S. D. Pagé, C. Pellerin and O. Lebel, J. Phys. Chem. B, 2009, 113, 14884-14891.

6 A. Laventure, G. De Grandpré, A. Soldera, O. Lebel and C. Pellerin, Phys. Chem. Chem. Phys., 2016, 18, 1681-1692.

7 A. Laventure, A. Soldera, C. Pellerin and O. Lebel, New J. Chem., 2013, 37, 3881-3889.

8 J. A. Zerkowski, C. T. Seto, D. A. Wierda and G. M. Whitesides, J. Am. Chem. Soc., 1990, 112, 9025-9026.

9 J. A. Zerkowski, C. T. Seto and G. M. Whitesides, J. Am. Chem. Soc., 1992, 114, 5473-5475.

10 J. A. Zerkowski and G. M. Whitesides, J. Am. Chem. Soc., 1994, 116, 4298-4304.

11 Q. Huo, K. C. Russell and R. M. Leblanc, Langmuir, 1998, 14, 2174-2186.

12 H. Koyano, P. Bissel, K. Yoshihara, K. Ariga and T. Kunitake, Chem. - Eur. J., 1997, 3, 1077-1082.

13 M. Gryl, S. Cenedese and K. Stadnicka, J. Phys. Chem. C, 2015, 119, 590-598.

14 S. Kohmoto, S. Sekizawa, S. Hisamatsu, H. Masu, M. Takahashi and K. Kishikawa, Cryst. Growth Des., 2014, 14, 2209-2217.

15 R. Laitinen, K. Löbmann, H. Grohganz, C. Strachan and T. Rades, Mol. Pharm., 2014, 11, 2381-2389.

16 V. Curtin, Y. Amharar, Y. Hu, A. Erxleben, P. McArdle, V. Caron, L. Tajber, O. I. Corrigan and A. M. Healy, Mol. Pharm., 2013, 10, 386-396.

17 J. L. Calahan, S. C. Azali, E. J. Munson and K. Nagapudi, Mol. Pharm., 2015, 12, 4115-4123. 
18 J. Cortese, C. Soulié-Ziakovic, S. Tencé-Girault and L. Leibler, J. Am. Chem. Soc., 2012, 134, 3671-3674.

19 Y. Kyogoku, R. C. Lord and A. Rich, Nature, 1968, 218, 69-72.

20 O. Lebel, T. Maris, M.-È. Perron, E. Demers and J. D. Wuest, J. Am. Chem. Soc., 2006, 128, 10372-10373.

21 J. D. Wuest and O. Lebel, Tetrahedron, 2009, 65, 7393-7402.

22 R. N. Eren, A. Plante, A. Meunier, A. Laventure, Y. Huang, J. G. Briard, K. J. Creber, C. Pellerin, A. Soldera and O. Lebel, Tetrahedron, 2012, 68, 10130-10144.

23 J. M. McGrath and M. D. Pluth, J. Org. Chem., 2014, 79, 711719.

24 D. B. Hibbert and P. Thordarson, Chem. Commun., 2016, 52, 12792-12805.

25 M. J. Hynes, J. Chem. Soc. Dalton Trans., 1993, 311-312.

26 L. Brunsveld, B. J. B. Folmer, E. W. Meijer and R. P. Sijbesma, Chem. Rev., 2001, 101, 4071-4098.

27 M. P. Summers, J. Pharm. Sci., 1978, 67, 1606-1610.

28 C. A. Angell and E. J. Sutter, J. Phys. Chem., 1971, 75, 18261833.

29 M. D. Ediger, J. Chem. Phys., 2017, 147, 210901.

30 T. G. Fox and P. J. Flory, J. Polym. Sci., 1954, 14, 315-319.

31 P. R. Couchman and F. E. Karasz, Macromolecules, 1978, 11, 117-119.

32 V. Kapko, Z. Zhao, D. V. Matyushov and C. Austen Angell, J. Chem. Phys., 2013, 138, 12A549.

33 S.-W. Kuo and H.-T. Tsai, Macromolecules, 2009, 42, 47014711.

34 A. V. Lesikar, J. Chem. Phys., 1977, 66, 4263-4276.

35 Y. Shirota, J. Mater. Chem., 2000, 10, 1-25.

36 J. Kerč and S. Srčič, Thermochim. Acta, 1995, 248, 81-95.

37 K. Pajula, M. Taskinen, V.-P. Lehto, J. Ketolainen and 0. Korhonen, Mol. Pharm., 2010, 7, 795-804.

38 J. P. Mathias, E. E. Simanek, J. A. Zerkowski, C. T. Seto and G. M. Whitesides, J. Am. Chem. Soc., 1994, 116, 4316-4325.

39 B. M. Craven, C. Cusatis, G. L. Gartland and E. A. Vizzini, J. Mol. Struct., 1973, 16, 331-342.

40 N. Zencirci, U. J. Griesser, T. Gelbrich, D. C. Apperley and R. K. Harris, Mol. Pharm., 2014, 11, 338-350.

41 R. Puig-de-la-Bellacasa, L. Giménez, S. Pettersson, R. Pascual, E. Gonzalo, J. A. Esté, B. Clotet, J. I. Borrell and J. Teixidó, Eur. J. Med. Chem., 2012, 54, 159-174.

42 M. Temprado, M. V. Roux, F. Ros, R. Notario, M. Segura and J. S. Chickos, J. Chem. Eng. Data, 2011, 56, 263-268.

43 S. M. S. Chauhan and N. G. Giri, Supramol. Chem., 2008, 20, 743-752. 